\title{
First Language Attrition Of Lexical Structures In A Contact Situation With English: A Study Among Anaañ Bilingual Children
}

\author{
Victoria Enefiok Etim \\ Department Of Linguistics And Nigerian Languages \\ University Of Calabar, Calabar, Nigeria \\ Bassey Andian Okon \\ Department Of Linguistics And Nigerian Languages \\ University Of Calabar, Calabar, Nigeria \\ Margaret Mary Okon \\ Department Of Linguistics And Nigerian Languages \\ University Of Calabar, Calabar, Nigeria
}

\begin{abstract}
This study examined first language (L1) Attrition of lexical items among bilingual children within Abak metropolis, Akwa Ibom State, Nigeria. First language (L1) attrition is the disintegration of the first language as a result of contact with second language (L2) or domination of the second language. The theories of language contact and language change and psycholinguistic question of accessibility is the theoretical framework for the study. An expo-facto design was used in the study and a purposive sampling was used to select 70 children from primary and secondary school of ages between 7 and 14 years who speak both English and Anaañ languages. Personality Background Questionnaire (PBQ), Ibadan Word list of 400 basic items and Picture Naming Task (PNT) were used to collect data for the study. This paper reveals that L1 attrition occurs as a result of non-constant usage of the L1 both at home and in school. Early exposure of the children to L2 also impedes their ability to fully develop the language of their mother tongue and consequently results in L1 attrition. The paper concludes that frequent use of $L 2$, negative attitude to $L 1$, motivation and age are the main reasons for lexical attrition in children. It is therefore recommended that the use of $L 1$ by parents with their children at home be encouraged and L1 be included in the school curriculum for pupils and students at primary and secondary schools in order to prevent $\mathrm{L1}$ attrition.
\end{abstract}

Key words: Lexical Structures, Language Attrition, Anaañ Language, Bilingual Children, Language Contact.

\section{INTRODUCTION}

First Language attrition is very common in our linguistic milieu though the research on it is very sparse as compared with the vast field of research on second language development. Researchers most times focus on the second language (L2) - how it is learned, how the first language (L1) has influenced it, why L2 learners so rarely become 'perfect', and so on. Meanwhile, an important concern that worth investigating also is on what happens to the native language if a child becomes bilingual.

Language attrition is closely if not completely considered to be a reversal of language acquisition. While language acquisition is the process by which an individual acquire the capacity to perceive, produce and use words to understand and communicate, language 
attrition on the other hand is the process by which the individual reduces or gradually loses the skills of his or her first language (L1) and the second language (L2) becomes more pronounced. Field [8] identifies Primary and Secondary language attrition. He says that primary language attrition particularly affects immigrant populations which arise as a result of extended exposure to a second language. This occurs in a situation where L1 is paid very little attention to. Another strong factor in the case of children's attrition is integrative motivation.

According to Dominguez [7], native language attrition has been reported in language contact situation as the result of linguistic pressures derived from extensive exposure to a second language, changes in input conditions (reduced exposure to L1 input or dominant L2 input), and infrequent use of the L1. Seliger \& Vago [31] observe that the beginnings of first language attrition can be traced to advanced stages of bilingualism or second language acquisition.

Often time researches on language attrition concentrate more on the native speakers, who migrate to a different country or territory, learn and become proficient in the second language (L2) while losing proficiency and fluency of the first language (L1). It is important to note that the same process of losing proficiency in L1 or a portion of it in the same native environment due to contact with L2 is also very possible. Language attrition according to De Bot and Hulsen [6] is therefore divided into L1 loss in an L1 environment, L1 loss in an L2 environment, L2 loss in an L1 environment and L2 loss in an L2 environment.

This study describes L1 loss in an L1 environment which is Anaañ in contact situation with English. Anaañ language is spoken in eight local government areas of Akwa Ibom State in Nigeria, where English language is used as an official language to promote cultural and linguistic unity in the country. English becomes the interconnecting language amongst Nigerians from different geopolitical zones and different ethnicities as Nigeria is a multilingual nation with about 521 languages. Gordon [10].

Brainbridge, [4] observes that English, as a second language in Nigeria, has developed at a very tremendous rate in the past two decades, which has gradually taken dominance over indigenous languages. Hence, to Akabogu and Mbah [1], one of the specific challenges for Nigeria concerning this, bothers on how to loosen the prominence given to the English language, as this would allow policy makers put in place reasonable measures to promote literacy in the indigenous languages and maintain cultural traditions and national identity. Due to the high prestige given to English, most children whose L1 is Anaañ language, tend to tilt towards the use of L2, which is English. Also, many elites' homes in Anaañ land encourage their wards to speak more of English than their native language, while on the other hand, most children only have access to the receptive aspect of their native language when their parents or elders are conversing. In the same vein, English is further used as the language of instruction in schools, churches, media, etc.

All these, have a deteriorative effect on the native language of the children and cause a less fluency in it. Thus, the thrust or main concern of this work, is to investigate the L1 attrition in the domain of lexicon among children, who, through language contact with English, have lost proficiency in the Anaañ language.

\section{Research questions}

1. To what extent has Anaañ children experience L1 attrition of lexicon in contact situation with English language?

2. What are the reasons for L1 attrition of lexical items among Anaañ children?

3. What are the effects of early exposure of Anaañ children to English language on L1? 


\section{Language attrition}

\section{LITERATURE REVIEW}

Language attrition is seen as changes in one's native language that has either fallen into linguistic underuse or is used alongside the environmental one. In view of this, Schmid \& Köpke [29] define attrition as a process that is driven by two factors: (a) the presence, development and regular use of a second linguistic system, leading to cross linguistic interference (CLI), competition and other effects associated with bilingualism, and (b) a decreased use of the attriting language, potentially leading to access problems. Schmid [30] adds that language attrition is of common linguistic phenomenon evident in virtually every part of the world, as languages of great culture and potency spread at the expense of less prestigious indigenous codes.

Pavlenko [24] defines First language attrition as the "loss of some L1 elements seen in the inability to produce, perceive, or recognize particular rules, lexical items, concepts or categorical distinctions due to L2 influence". Kopke [19] goes further to say that L1 attrition involves temporary or permanent changes of the first language as a result of overuse of the second language. Similarly, Seliger [31] refers to attrition as "the temporary or permanent loss of language ability as reflected in a speaker's performance or in his or her inability to make grammaticality judgments that would be consistent with native speaker monolinguals at the same age and stage of language development".

Language attrition according to Schmid [28] describes the loss of, or changes to grammatical and either features of a language as a result of declining use by speakers who have changed their linguistic habits. In such a situation there may for example, be simplification in the tense system, lexicon, or in certain properties of subordinate clauses; some vocabulary items might fall into disuse and phonetic features may be restructured. In the opinion of Freed [9] language attrition, language regression or language erosion, may refer to the loss of any language or any the portion of a language by an individual or a speech community whether, because of aphasia, aging or for any social catastrophic, or political reasons. The term 'loss' is problematic in another way, particularly when used within the context of linguistic research. Language loss may be an accurate term for the phenomenon of change or reduction of linguistic knowledge by emigrants. It is however, somewhat unspecific, as the same term can also refer to the shift from one language to another in a community over several generations, or to the overall extinction or death of a particular language.

\section{THEORETICAL FRAMEWORK}

According to Schmid and de Bot [27], there are predominantly four theoretical models and frameworks available to the study of language attrition. These are: i) Jakobson's Regression hypothesis, ii) Language contact and language change, iii) Universal Grammar and parameter setting, iv) Psycholinguistic Questions of Accessibility.

However, Schmid and de Bot [27] observe that the division between these frameworks cannot be drawn as neatly as the list might lead one to suspect. Often theories overlap, or features of an observed attritional variety can equally be accounted for by several of these theories or by an interaction of them. In this work, two of the above mentioned theories - Language contact and language change as well as psycholinguistic question of accessibility will interact in the analysis of the data.

\section{Language Contact and Language change}

In Schmid and de Bot's [27] opinion in the situation of language contact and ensuing language change is that the modifications that can be observed in the linguistic system of one of these 
languages are entirely or in parts due to one language encroaching on the other. According to Kim [17], one of the most widespread notions in L1 attrition is that L1 attrition is a language contact phenomenon that occurs within the bilingual speaker's minds. The two languages in contact are considered to co-exist in a state of competition which finally leads to dominance of L2 on the linguistic domains of L1, and to the ensuing attrition and sometimes death of L1. Studies of attrition within this framework is based on a comparison of linguistic features of L1 and L2, trying to isolate phenomena that can only be due to inter-language effects against mistakes that are internally induced. The two hypothesis formulated in this theory are:

1. Features that are cognate in L1 and L2 are more likely to be retained while categories that do not have an equivalent in the $\mathrm{L} 2$ will be lost both in language attrition and language death. (Andersen, [2], Romaine [25]).

2. At a certain stage in language attrition, due to lack of input in the attriting language (AL), the grammar of the non-attriting language (NAL) will become a source of "indirect positive evidence" which will affect grammaticality judgments in the AL.

Jamshida \& Marefat [14] note that L1 attrition occurs as a natural outcome of acquiring another language but this does not mean that the process is an automatic consequence of acquiring another language.

\section{Psycholinguistic Questions of Accessibility}

According to Schmid and Köpke [29], Psycholinguistics research has established that bilingual's process language in a way which is fundamentally different from that of monolinguals, in that corresponding lexical items in all language systems are always active to some degree, no matter which language is being used or accessed. De Bot and Hulsen [6] observes that this psycholinguistic aspect of L1 attrition have received little attention until now, despite the fact that the evidence available suggests that attrition may be psycholinguistic in nature.

The psycholinguistic model of language attrition augments the perspectives on language internal and acquisitonal factors by taking into account features of processing and memory retrieval, dealing with more general psychological issues like the accessing and forgetting of information. (Schmid \& de Bot [27]).

Researchers in Language attrition have made effort to answer the question of whether evidence for attrition is evidence for something being irretrievably "lost" or merely an indication of a temporary problem of accessibility. This is related to competence and performance. ie whether attrition merely affects procedural knowledge (performance) or whether the actual knowledge of a language (competence) can be deteriorated. (Ammerlaan, [3]). Köpke and Schmid [19] add that insights into the internal reasons for language attrition might help gain a better understanding of the mechanisms underlying language processing and their interaction with respect to two languages that can be considered to be in competition.

In explaining the factors possibly considered in language attrition from the psycholinguistic point of view, Köpke and Schmid [19], postulate Critical Period Hypothesis, Competence vs performance and Critical Period Hypothesis.

\section{Critical Period Hypothesis (CPH)}

According to Köpke and Schmid [19], Critical Period Hypothesis assumes that due to brain maturation constraints, L2 learning becomes more difficult past a certain period. This is because, age is one important factors to be considered when it concerns psycholinguistic model of language attrition. On that note, Kaufman [18] asserts that attrition of L1 among older 
children and adults differs from the $\mathrm{L} 1$ attrition process among pre-puberty children. If there is one thing for which there seems to be ample converging evidence, it is that L1 attrition in children is much more severe than in adults.

\section{Competence vs Performance}

Köpke and Schmid [19] observe that the first scholar who drew attention to the necessity of taking into account the distinction between competence and performance with respect to attrition data as early as 1983 was Sharwood Smith. The study of language attrition within this framework tend to make distinction between the loss of the underlying mental representation (competence attrition) and the loss of control of that underlying mental representation (performance attrition). The claim that attrition leads to change in the underlying grammatical knowledge (competence) is linked mostly with reference to incomplete learners (Smith [33]; Chomsky [5]) whose mother tongue may not have fully matured and stabilized as a result of shift to the majority language (de Bot and Hulsen [6]).

Attrition at the level of competence concerns underlying linguistic competence and entails a restructuring of what is known about the language. And at the level of performance (or processes), attrition results in difficulties in control of that knowledge (which may remain intact) (Seliger [31]; \& Ammerlaan [3]).

\section{Activation Threshold Hypothesis (ATH)}

Jamshida and Marefat [14] in Kopke [16] state that the Activation Threshold Hypothesis was initially proposed by Paradis [21]; [22] to account for differential recovery in polyglot aphasia, and only recently has the theory been applied to the study of language attrition. It assumes that items (or languages) that are more frequently activated need less stimulation to be reactivated than items (or languages) that are less frequently activated. (Paradis, [21;22;23]).

Language attrition occurs as a result of long-term absence of stimulation of one of the languages of the bilingual. It should be noted that this does not mean that the linguistic system of the bilingual is completely lost due to inhibition or a high activation threshold (Green, [12]). Depending on the frequency of use, different linguistic items within the same language might require various degree of stimulation in order to become activated (Paradis, [21]).

\section{METHODOLOGY}

Purposive sampling was used to select pupils and students from Convent Primary School, Abak and Government Secondary School, Ediene Abak for the study. The participants were between the ages of 7 and 14 years. At this age, it is presumed that they have completed their stage of language acquisition. The subjects were in two groups - the Study Group (SG) and the Control Group (CG) which we also term as the bilinguals and the monolinguals. The SG consists of the bilingual children who speak Anaañ and English while the CG is made up of children who speak more of Anaañ than English. The CG is brought in so as to compare the degree of L1attrition among the bilingual children of Anaañ. They were therefore selected for comparative purpose. Sixty participants ( 40 girls and 20 boys) in the SG were selected through purposive sampling from the two schools. This was done by requesting that those who are bilinguals to stand. The selected ones were further interviewed to really be sure that they speak both English and Anaañ. From the personal interview, the subjects in SG use both English and Anaañ as medium of communication at home, in school, with peers and watch English movies. Subjects in CG who were selected for comparative purpose were 10 in number ( 6 girls, 4 boys) of the same age bracket with those in SG. They were selected from the same schools, using the same method of one to one interview. The selected subjects speak Anaañ all the time at home and in the public. 
The instruments used in the collection of data were Personal Background Questionnaire (PBQ), vocabulary tests of Picture Naming-Tasks (PNT) and Ibadan Word List of 400 basic items. The PBQ consists of the name of the participant, date of birth, gender, place of birth, tribe of parents, and level of education of parents. Other personal questions were also included in the questionnaire such as preferred language of choice of the pupils when communicating with friends, family members, and in the public. The frequency of use of L1 and preferred language to identify with. The PNT is made up of 30 pictorial items which contain colours, plants, animals and parts of body. The 400 word list was modified before presenting to the participants. Ambiguous, unfamiliar and function words were dropped leaving 300 grammatical lexical items for the participants to read and translate in Anaañ. The word list and PNT were given to the participants in the study group (SG) and control groups (CG) to test the extent of L1 attrition in Anaañ lexical items while the PBQ was given to only the children in the SG.

\section{ANALYSIS AND DISCUSSION OF RESULT}

The data collected was analyzed and results presented according to the research questions for a clearer understanding.

Research question 1: To what extent do Anaañ children experience L1 attrition of lexicon in contact situation with English language?

The result of the data analysis provided in tables 1,2 and 3 are used in providing answer to the research question 1

TABLE 1

Population t-test of the $\mathrm{L1}$ attrition of lexical items using word list among Annañ children in Abak metropolis of Akwa Ibom State, Nigeria

\begin{tabular}{lcrrrrrr}
\hline Variable & $\mathrm{N}$ & Mean & $\begin{array}{c}\text { Std. } \\
\text { Deviation }\end{array}$ & $\begin{array}{c}\text { Std. Error } \\
\text { Mean }\end{array}$ & $\mathrm{t}$ & $\mathrm{df}$ & $\mathrm{p}$-value \\
\hline $\begin{array}{l}\text { L1 Attrition } \\
\text { Level }\end{array}$ & 70 & 64.41 & 35.645 & 4.641 & -39.993 & 59 & .000 \\
\hline
\end{tabular}

Table 1 shows the result of the population t-test of the analysis of the data collected with respect to the L1 attrition of lexical items using words list among Annan children in Abak metropolis, Akwa Ibom State, Nigeria. A cut off point of 250 correct words was set as the pass mark for the participants. The sample mean was compared against the pass mark at .05 alpha level. A population- $t$ value of -33.99 at $d f=59$ and $p<.05$ was obtained which indicated that there is a significant high L1 attrition of lexical structures among Annan children. This implies that there is an overall decrease in the L1 vocabulary among Annañ children in Abak metropolis of Akwa Ibom State, Nigeria.

TABLE 2

Population t-test of the $\mathrm{L} 1$ attrition of lexicon using picture recognition among Annañ children in Akwa Ibom State, Nigeria

\begin{tabular}{lccccccc}
\hline Variable & $\mathrm{N}$ & Mean & $\begin{array}{c}\text { Std. } \\
\text { Deviation }\end{array}$ & $\begin{array}{c}\text { Std. Error } \\
\text { Mean }\end{array}$ & $\mathrm{T}$ & Df & $\mathrm{p}$-value \\
\hline $\begin{array}{l}\text { L1 Attrition } \\
\text { Level 2 }\end{array}$ & 70 & 10.62 & 3.632 & .469 & -30.678 & 59 & .000 \\
\hline
\end{tabular}

Table 2 shows the result of the population t-test of the analysis of the data collected with respect the L1 attrition of lexicon in contact situation with English language using picture 
recognition among Annañ children in Akwa Ibom State, Nigeria. This result also indicates that a population-t value of -30.68 at $\mathrm{df}=59$ and $\mathrm{p}<.05$ was obtained which indicated that there is a significant high L1 attrition of lexicon in contact situation with English language among Annañ children. This also support that there is a significant high extent to which L1 attrition of lexicon exist among Annan children.

TABLE 3

Independent t-test of $\mathrm{L} 1$ attrition of lexicon between the Bilinguals and the Monolinguals of Annañ children in Abak metropolis, Akwa Ibom State, Nigeria

\begin{tabular}{llrrrrrr}
\hline Variable & Category & $\mathrm{N}$ & \multicolumn{1}{c}{ Mean } & Std. Deviation & $\mathrm{T}$ & Df & p-value \\
\hline L1 Attrition & monolinguals & 10 & 27.30 & 3.093 & 13.700 & \multirow{2}{*}{68} & \multirow{2}{*}{.000} \\
Level 2 & bilinguals & 60 & 10.62 & 3.632 & & & \\
\hline
\end{tabular}

Table 3 shows the independent t-test of the L1 attrition between the SG and the CG. This result shows that the mean score of the children in the Control Group who are frequent users of Annan are higher in terms of correct responses to the test of picture naming and vocabulary test than the children in SG who seldom use Anaañ language to communicate. This implies that the children in the SG experience more attrition than those in CG. The result gives a comparative independent $\mathrm{t}$-value of $13.70 \mathrm{at} \mathrm{df}=68$ and $\mathrm{p}<.05$. This indicates that there is a significant difference in L1 attrition between children who use the Annañ language frequently and those who do not use it frequently.

Research question 2: What are the reasons for L1 attrition of lexical items among Anaañ children?

The result in table 4 provides the basis for the answer to research question 2

TABLE 4

Descriptive analysis of percentage, mean and SD of the reasons for $\mathrm{L1}$ attrition of lexicon in contact situation with English language

\begin{tabular}{|c|c|c|c|c|c|c|c|c|}
\hline $\mathrm{S} / \mathrm{N}$ & Variables & $\begin{array}{l}\text { SD } \\
\%\end{array}$ & $\begin{array}{l}\mathrm{D} \\
\%\end{array}$ & $\begin{array}{l}\mathrm{A} \\
\%\end{array}$ & $\begin{array}{l}\text { SA } \\
\%\end{array}$ & $x$ & SD & $\begin{array}{l}\text { Remarks on } \\
\text { group }\end{array}$ \\
\hline 1. & I avoid speaking Anaañ in the public & 1.7 & 8.3 & 63.3 & 26.7 & 3.08 & .79 & Negative Attitude to L1 \\
\hline 2. & $\begin{array}{l}\text { I try to speak Anaañ confidently only } \\
\text { with my parents and siblings at home }\end{array}$ & 3.3 & 6.7 & 31.7 & 58.3 & 3.42 & .85 & Lack of frequent usage \\
\hline 3. & $\begin{array}{l}\text { I feel shy to speak Anaañ outside our } \\
\text { home }\end{array}$ & - & 3.0 & 36.7 & 58.3 & 3.48 & .75 & Lack of frequent usage \\
\hline 4. & $\begin{array}{l}\text { I don't know some words in Anaañ } \\
\text { because I was exposed to English } \\
\text { early }\end{array}$ & 3.3 & 3.3 & 33.3 & 60 & 3.50 & .73 & $\begin{array}{l}\text { Too early Exposure to } \\
\text { L2 }\end{array}$ \\
\hline 5. & I feel that English is better than Anaañ & 10 & 20 & 41.7 & 28.3 & 2.78 & 1.08 & Negative Attitude to L1 \\
\hline 6. & $\begin{array}{l}\text { Frequent use of English makes me } \\
\text { less fluent in Anaañ language }\end{array}$ & - & 1.7 & 36.7 & 61.7 & 3.58 & .59 & Lack of frequent usage \\
\hline 7. & $\begin{array}{l}\text { English is a more prestigious language } \\
\text { than Anaañ }\end{array}$ & 5 & 10 & 38.3 & 46.7 & 3.22 & .94 & Negative Attitude to L1 \\
\hline 8. & $\begin{array}{l}\text { When I speak Anaañ, my friends laugh } \\
\text { at me }\end{array}$ & - & 13.3 & 38.3 & 48.3 & 3.22 & .99 & Lack of motivation \\
\hline 9. & $\begin{array}{l}\text { I can hardly complete a sentence in } \\
\text { Anaañ without switching to English }\end{array}$ & - & 1.7 & 26.7 & 71.7 & 3.68 & 5.70 & Code switching \\
\hline 10. & $\begin{array}{l}\text { My parents do not encourage me to } \\
\text { speak Anaañ language }\end{array}$ & 1.7 & 11.7 & 45 & 41.7 & 3.17 & .94 & Lack of motivation \\
\hline
\end{tabular}


Table 4 shows the various reasons for L1 attrition of lexicon among Anaañ bilingual children. The number of students and their level of agreement/disagreement were expressed in percentages (\%). The mean and standard deviation of each of the items of the reasons for L1 attrition was also provided. The percentages of most of the items were higher for Agree and Strongly Agree to the reasons adduced for L1 attrition. The mean statistically show that all the reasons suspected to account for the L1 attrition were highly agreed to because the mean of each of the items were all above the average mean 2.5 of the item responses. It is clearly indicated that negative attitude towards L1, lack of frequent usage, too early exposure to L2, code switching and Lack of motivation are the reasons for L1 attrition among Anaañ bilingual children.

From the above analysis, two factors stand out among the listed reasons which impact strongly on L1 attrition among Anaañ bilingual children. These are (i) attitude and motivation (ii) Age at onset of bilingualism and language use.

\section{Attitude and motivation}

Attitude and motivation have been shown to have a strong impact on language learning. Köpke \& Schmid [19]. A negative attitude towards a language can prove detrimental to the development or maintenance of the language, while those with positive attitude towards their L1 maintain towards additive bilingualism. Out of sixty children interviewed, the mean statistics for negative attitude towards Anaañ language is above average. This suggests that the language is potentially endangered. A language is potentially endangered if there are few children learning the language with positive attitude and motivation to speak it frequently. If immediate measures are not put in place, this can ultimately lead to the death of the language.

\section{Age at onset of bilingualism and language use}

Age at onset of bilingualism is one of the important variables determining language learning and language attrition. The age at which a child is exposed to $\mathrm{L} 2$ is an important factor as far as psycholinguistic point of view is concerned. Due to this early exposure of children to L2, Genesee \& Nicoladis [11] observe that the rate of language development is slowed down in bilingual first language learners in comparison to monolingual learners.

In most homes in Anaañ land, the use of English language takes dominance in communication with very minimal use of Anaañ which has constituted as one of the reasons for erosion of Anaañ in the mind of children. From the interview conducted on the children in two schools in Abak metropolis, the result shows that lack of frequent usage of Anaañ language is a strong factor responsible for the displacement of the L1 by the L2 (English). There is no doubt, therefore, that children whose mother tongue has not fully matured and stabilized as a result of shift to the majority language are undergoing a change in their underlying grammatical knowledge (ie competence attrition) in the native language. This confirms the assertion of Hansen \& Kurashige [13] which says that rapid attrition of unused language skills is the rule for young children especially when they have attained only a low proficiency level in the waning language.

Research Question 3: What are the effects of early exposure of Anaañ children to English language on L1?

From the data gathered during the study, there are two major categories of interference identified to be the consequences of early exposure of Anaañ children to L2. These are borrowing/loan words and intralingual errors of substitution. 


\section{Borrowing/loan words}

Loan words are words that are borrowed from a donor language and used by the recipient language to refer to and mean what the words refer to and mean in the donor language. Kari [15]. In this study, the children made use of lots of loan words from the English language in the two vocabulary tests (word list and picture naming). Some examples are shown in table 5.

TABLE 5

Lexicon attrition through borrowed word

\begin{tabular}{lll}
\hline Attrition lexicon & Anaañ & English \\
\hline àpọ̀pọ́ & údíá édì & 'Paw paw' \\
árò & íràn & 'arrows' \\
yélò & ùtò-ùtò & 'yellow' \\
dọ́ktọ̀ & áwìà-íbọ̀k & 'doctor' \\
fláwà & mfùd & 'flower' \\
fédà & ntàñ & 'feather' \\
àyọ́n & úkwọ̀kkọ̀-àfộñ & 'iron' \\
\hline
\end{tabular}

From the above examples, the lexical borrowings by those children are as a result of the L2 influence on the native language. These children tend to condition the structures of the words they do not know to suit the sound patterns and syllable structures of Anaañ. It is also a sign of language attrition because those items have names in Anaañ but the children do not know what they are called especially as they were not exposed to them.

\section{Substitution}

The children in some cases provided answers by giving names of items which resembles the object presented to them or they give a general word instead of the specific name for the object. They used incorrect names which they know share some semantic features with the items presented to them. Examples are as given in table 6.

TABLE 6

Lexicon attrition of words through substitution

\begin{tabular}{lll}
\hline Attriting lexicon & Anaañ & English \\
\hline úbọ́k & ìtọ́ñ-úbọ̀k & 'arm' \\
úkód & ìfúkọ̀ & 'thigh' \\
úfọ̀k & ùbèèd & 'room' \\
ùbáhàsèn & ùsìré & 'dawn' \\
àkónèjò & èkúm & 'darkness' \\
ídúñ & ísọnñ & 'village' \\
ébọ̀k & ídiòk & 'Gorilla' \\
\hline
\end{tabular}

As shown in the above data, the bilingual children substituted the correct words with the more general and familiar words to them. This also signals language attrition.

\section{SUMMARY AND CONCLUSION}

The study on first language attrition of lexical structures in contact situation with English among Anaañ bilingual children investigated the rate of lexical attrition and compared the vocabulary knowledge of the children in the SG with those in the CG. Table 1 of the population t-test shows the result of the data collected from the children in the SG and in CG using the modified word list. The population $t$ value of -33.99 at $\mathrm{df}=59$ and $\mathrm{p}<.05$ was obtained. This shows that there is a significant high language attrition among Anaañ children. Table 2 shows the result of the population t-test of the analysis of the picture naming-task collected from the 
two groups. The result also indicated $t$ value of -30.68 at $\mathrm{df}=59$ and $\mathrm{p}<.05$ which signals a significant high language attrition among the Anaañ children. Table 3 shows the independent $t$ -test between the bilingual group and the control group. The comparative analysis of the data from the word list and picture naming-task gives the independent t-value of 13.70at $\mathrm{df}=68$ and $\mathrm{p}<.05$ which indicates that the bilingual children are experiencing developmental attrition as they exhibit an overall less extensive vocabulary knowledge of the native language than the children in the control group.

The study also investigated the reasons for L1 attrition among Anaañ bilingual children using the PBQ. From the result of the interview, Table 4 shows the reasons for L1 attrition using percentages, mean and standard deviation to analyse the responses of the bilingual children. The mean statistically showed that negative attitude, lack of frequent usage of the native language, early exposure to L2, code switching and lack of motivation are the reasons for L1 attrition. However, two main factors stand out among the enlisted reasons. These are i) Attitude and motivation. (ii) Age at onset of bilingualism and language use.

The study also examined the effects of early exposure of Anaañ bilingual children to English language. This shows that there are inter-language errors and interferences that are internally induced. The bilingual children make use of loan words extensively. Words like feda - feather, aro - arrows, flawa - flower, etc. they try to adjust them to conform to the phonological rules of Anaañ. However, the children in the CG were able to provide the appropriate names to those lexical items. The study confirms competence attrition in the mother tongue of the bilingual children (whose mother tongue has not fully matured) as a result of early bilingualism and lack of adequate exposure to the native language.

From the foregoing, it is obvious to note that lexical borrowing which the bilingual children exhibited greatly is as a result of early contact with English language, considering the fact that the children in the CG were able to give corresponding answers to the items. Other variables identified as factors responsible for L1 erosion in Anaañ bilingual children are as a result of L2 influence on the native language, negative attitude towards the L1 and non-frequent use of the language.

It is interesting to note that these bilingual children are ignorant of the fact that they are not proficient in their native language. The study brought the awareness to them and made them conscious of their loop holes in the knowledge of their native language.

\section{RECOMMENDATIONS}

The following recommendations were therefore made based on the conclusion of the findings of the study:

1. Teachers, through policy makers be made to provide similar tasks to the students from time to time and Anaañ language be added to the curriculum for teaching in Primary and Secondary schools in Anaañ speaking Local Government Areas of the State.

2. Parents also be educated to contribute in the development and maintenance of Anaañ language by providing and encouraging quality L1 input of their wards from early years, rather than encouraging $\mathrm{L} 2$ use at home.

\section{References}

Akabogu,J.U., \& Mbah, B.M. (2013). Second language acquisition, Attrition of indigenous Languages in Nigeria: Cultural implications. 10SR Journal of Humanities and social Sciences. (10SR-JHSS).vol. 13. Pp 01-05

Anderson, R.W. (1982). Determining the linguistic attributes of language attrition. In R.D.Lambert \& B.F.Fred (eds.), The loss of language skills. Rowley, MA: New bury House publishers. 
Ammerlaan, T. (1996). "You get a bit wobbly...Exploring, bilingual lexical retrieval Processes in the context of language attrition”. PhD dissertation, katholieke universiteit Nigemegen. Online version, Retrieved: November, 2017.

Brainbridge, S. B. (2014). Second language acquisition and current trends in Japan, the cultural risks. Journal roll.Enging Nohon University. Retrieved from online version: www.researchgate.net.

Chomsky, N. (1985). The minimalist Program. Cambridge: MIT Press.

De Bot, K., \& Hulsen, M. (2002). Language Attrition: tests, self-assessments and perceptions, International journal of Bilingualism 8, $321-345$

Dominguez, L. (2013). Understanding Interfaces Second Language Acquisition and first Language Attrition of Spanish subject realization and word order variation. Amsterdam: John Benjamin's publishing Company.

Field, J. (2004). Psycholinguistics: The Key concepts. London: Routledge.

Freed, B.F. (1983). Language loss: Current thoughts and future direction. In R.D. Lambert \& B.F. Freed (Eds.) The loss of Language skills, Rowley, M.A. Newbury House.

Gordon, R. (2005). Ethnologue:Language of the world, Dallas, Tex: SIL International online version. Retrieved on November, 2017

Genesee, F. \& Nicoladis, E. (2001). Bilingual First Language Acquisition. Online version- www. Psych.mcgll.ca. Retrieved on November, 2017

Green, D. W. (1986). Control, Activation and Resource: A framework and a Model for the Control of Speech in Bilinguals. Brain and Language, 27,210-223

Hansen, L. \& Reetz-Kurashige, A. (1999). Investigating second language Attrition: An Introduction. In Hansel, L. (Ed) Second language attrition in Japanse contexts. New York: Oxford University press, inc.

Jamshidiha, H., \& Marefat, H. (2006). L1 Perian Attrition University of Tehran, Iran in Linguistics Journal, vol1. Retrieved from www.linguistics.journal.com on November 2017 Kari, E.E. (2015). Morphology: An Introduction to the study of word structure. Port Harcourt: University of Port Harcourt Press Ltd.

Kopke, B. (2004). Neurolinguistic aspects of attrition. Journal of Neurolinguistics 17, 3.30

Kim, S.H. (2007). First Language attrition in a second language learning environment: The case of Korean-English late Bilinguals. Doctoral Dissertation at the University of Auckland. Online version. Retrieved; September, 2017

Kaufman (2001). “Tales of L1 Attrition: Evidence from Pre-puberty children.” In T. Ammerlaan, M., Hulsen, H. Strating and K. Yagmur (eds), sociolinguistic and psycholinguistic perspectives on maintenance and loss of minority languages. Münster: Waxmann. Verlay GmbH.

Kopke, B. \& Schmid, M.S. (2004). First Language attrition: in M.S. Schmid, B. Koke, M. Keijzer, M.\& L. Weilemar (Eds.), First Language attrition: Interdisciplinary perspectives on methodological issues. Amsterdam: John Benjamins

Lambert, R.D. \& Freed, B.R. (1982). The loss of language skills. Rowley, Massach Ussetts Newbury House publishers.

Paradis, M. (1993). Linguistic, psycholinguistic, and neurolinguistic aspects of 'interference' in Bilingual speakers: The Activation Threshold Hypothesis. International Journal of Psycholinguistics 9 (2), 133-145

Paradis, M. (1985). On the representation of two languages in one brain. Language sciences. International journal of psycholinguistics 7:1-39

Paradis, M. (2001). An integrated neurolinguistic Theory of Bilingualism. LACUS Forum, 27:5-15

Pavelenko, A. (2004). L2 influence and L1 attrition in adult bilingualism. In Schmid, M.S.,Kopke, B., Keijzer, M., \& Weilemar, L. (eds). First language attrition: interdisciplinary perspectives on methodological issues. Amsterdam: John Benjamins. 47-59

Romaine, S. (1989). The language of the children and Adolescents. Oxford: Basil Blackwell

Ritchie, W.C. \& Bhatia, T.K.(2013). The handbook of Bilingualism and Multilingualism. West Sussex: John Wiley \& sons. Ltd. Publication

Schmid, M.S. \& de Bot, K. (2004). Language attrition. In a Davies \& C. Elder (Eds). The Handbook of Applied Linguistics. Oxford: Blackwell publishing

Schmid, M.S. (2011). Language attrition. New York: Cambridge University press 
Etim, V. E., Okon, B. A., \& Okon, M. M. (2018). First Language Attrition Of Lexical Structures In A Contact Situation With English: A Study Among Anaañ Bilingual Children. Advances in Social Sciences Research Journal, 5(6) 555-566.

Schmid. M.S. \& Köpke, B. (2007). Bilingualism and attrition. In B.Köpke, M.S. Schmid, M. Keijzer \& S. Dostert (es) language attrition: Theoretical perspective PP-1-8. Amsterdam/Philadelphia: John Benjamins.

Schmid, A. (1991).Language attrition. In linguist in Buoma Fijan and vago (eds). First language Attrition.

Cambridge: CUP

Seliger, H.L. (1996). Primary language acquisition in the context of bilinguals. In Ritchie,W.C., \& Bhatia, T.K. (eds) Handbook of second language acquisition. San Diego, C.A: Academic press, 605-626.

Seliger, H.W. \& Vago, R.M. (1991). "The study of First Language Attrition: An overview”. In Selinger, H.W. \& Vago, R.M. Vago (Eds.) First language attrition: Structural and Theoretical Perspectives. New York: Cambridge University Press

Smith, S. (1985). The Minimalist Program. Cambridge: MIT Press 